\title{
The difficult airway in obstetrical anesthesia: advocacy to improve the quality of assessment
}

\author{
Mathieu Boutonnet, MD • Pierre Pasquier, MD • \\ Sylvain Ausset, MD · Jean-Pierre Tourtier, MD
}

Received: 7 July 2011 / Accepted: 9 August 2011/Published online: 25 August 2011

(C) Canadian Anesthesiologists' Society 2011

\section{To the Editor,}

We read with great interest the study by McKeen et al. reporting on difficulties related to tracheal intubation in obstetrical anesthesia. ${ }^{1}$ We congratulate the authors on the quality of this study, particularly considering the high volume of cases they reviewed. The results are reassuring since the incidence of failed or difficult tracheal intubation was similar to that observed in the general population, and it remained stable during the 20 -yr sampling period. These findings should provide some reassurance to diminish operator stress typically encountered when managing the airway in obstetrical anesthesia. Nevertheless, airway management in obstetrical anesthesia remains a challenge, particularly in the emergency context, with implications for both neonatal and maternal morbidity if airway management is difficult and prolonged. The reduced functional residual capacity in the term parturient increases the risk of rapid hypoxemia to $<60 \mathrm{sec}$ in the peri-induction setting. ${ }^{2}$ Thus, anticipation is a key element toward successful outcomes in obstetrical anesthesia.

Despite recognized limitations of bedside airway assessment to predict difficult tracheal intubation, it is essential to anticipate potential difficulties in both the general surgery and obstetrical population. Each test used to assess airway conditions has a poor to moderate discriminative capability when performed in isolation. However, this discriminative power can increase incrementally by the combined use of several tests. ${ }^{3}$ In the study

M. Boutonnet, MD $(\bowtie) \cdot$ P. Pasquier, MD · J.-P. Tourtier, MD Hôpital d'Instruction des Armées du Val-de-Grâce, Paris, France e-mail: mathieuboutonnet@hotmail.com

S. Ausset, MD

Hôpital d'Instruction des Armées Percy, Clamart, France reported by McKeen et al., it was notable that only $16.8 \%$ of the charts of patients who underwent tracheal intubation included complete airway documentation. However, the extent of incomplete documentation of airway assessment has been reported previously in a study evaluating the quality of anesthesia records in Aquitaine, France. ${ }^{4}$ In that study, $<30 \%$ of the 3,193 patient files evaluated from 64 health care settings had an explicit conclusion concerning airway management. Mallampati classification was documented in $76 \%$ of the charts, whereas mouth opening and thyromental distance were recorded infrequently (36\% and $11 \%$ of files, respectively). In June 2005, the Haute Autorité de Santé in France developed a frame of reference for evaluation of professional practice to improve quality of care in anesthesia. ${ }^{5}$ Airway assessment is one of ten items evaluated to assess the quality of anesthesia records. Given this international context, it would be interesting to know whether the quality of airway evaluation in McKeen's study was stable or variable during the 20 -yr period of data collection and, furthermore, whether policies exist in Canada or are being developed to increase the rate of complete airway evaluation.

Conflicts of interest None declared.

\section{References}

1. McKeen DM, George RB, O'Connell CM, et al. Difficult and failed intubation: incident rates and maternal, obstetrical, and anesthetic predictors. Can J Anesth 2011; 58: 514-24.

2. Bernard F, Louvard V, Cressy ML, Tanguy M, Mallédant Y. Preoxygenation before induction for cesarean section (French). Ann Fr Anesth Reanim 1994; 13: 2-5.

3. Shiga T, Wajima Z, Inoue T, Sakamoto A. Predicting difficult intubation in apparently normal patients: a meta-analysis of 
bedside screening test performance. Anesthesiology 2005; 103: 429-37.

4. Hubert B, Ausset S, Auroy Y, Billard-Decré C, Tricaud-Vialle S, Djihoud A. Quality indicator survey of anaesthesia records in hospitals of Aquitaine (French). Ann Fr Anesth Reanim 2008; 27: 216-21.

5. Haute Autorité de Santé. Référentiel de Pratiques Profesionnelles. Tenue du dossier d'anesthésie. Juin 2005. L'utilisation partielle ou totale de ce référentiel nécessite l'accord préalable des promoteurs (CFAR et SFAR). Available from URL: http://www.has-sante.fr/ portail/upload/docs/application/pdf/2009-10/dossier_anesthesie_ ref.pdf (accessed July 2011).

\section{Reply}

We appreciate and thank Dr. Pasquier et al. for their interest and comments on our recently published study. ${ }^{1}$ We congratulate their national initiative to improve quality of anesthesia care and documentation of airway management by including it as part of a ten-point professional practice evaluation. We are unaware of any similar national initiative in Canada. In the Guidelines to the practice of anesthesia-Revised edition 2011, the Canadian Anesthesiologists' Society recommends that findings on pre-anesthetic assessments should be documented by the physician, but it does not specifically identify preoperative airway evaluation. $^{2}$

In response to Dr. Pasquier et al.'s query, we reviewed our data set to determine whether the rate of preoperative documentation changed over the 20-year period. We did find a significant improvement in the rate of anesthetic records documenting a preoperative airway assessment $\left(\chi^{2}\right.$ test for trends $P<0.0001$ ), i.e., from $0.1 \%$ in the first phase (1984-1988) to $10.7 \%$ in the second (1989-1993), $83.3 \%$ in the third (1994-1998), and $81.6 \%$ in the fourth (1999-2003) phase.
The publications of Samsoon et al. in 1987 and then of Hawkins et al. in 1997 likely had a significant impact on how our colleagues evaluated the obstetric airway and on their understanding of airway-related risk and anesthesiarelated mortality. ${ }^{3,4}$ Also, in 2000, our institution implemented electronic anesthesia records, which also contributed to improved recording of preoperative airway evaluations. We are currently in the process of implementing a new anesthesia information system, and we plan to evaluate further the impact of such systems on patient management.

Financial support None.

Competing interests None declared.

\section{References}

1. McKeen DM, George RB, O'Connell CM, et al. Difficult and failed intubation: incident rates and maternal, obstetrical, and anesthetic predictors. Can J Anesth 2011; 58: 514-24.

2. Merchant $R$, Bosenberg $C$, Brown $K$, et al. Guidelines to the Practice of Anesthesia: Revised edition 2011. Can J Anesth 2011; 58: 74-107.

3. Samsoon GL, Young JR. Difficult tracheal intubation: a retrospective study. Anaesthesia 1987; 42: 487-90.

4. Hawkins JL, Koonin LM, Palmer SK, Gibbs CP. Anesthesiarelated deaths during obstetric delivery in the United States, 1979-1990. Anesthesiology 1997; 86: 277-84.

Dolores M. McKeen, MD

Ronald B. George, MD

Colleen M. O'Connell, PhD

Victoria M. Allen, MD

Murray Yazer, MD

Meghan Wilson, MD

Tom C. Phu, MD

IWK Health Centre, Dalhousie University, Halifax, Canada 